\title{
Load-carrying capacity test of a long-span timber truss
}

\section{Jorge M. Branco PhD}

Assistant Professor, ISISE, Department of Civil Engineering, University of Minho, Guimarães, Portugal (corresponding author: jbranco@civil.uminho.pt) Humberto Varum PhD

Full Professor, CONSTRUCT-LESE, Faculty of Engineering (FEUP), University of Porto, Porto, Portugal
Vitor Ramisote MSC

Engineer, Department of Civil Engineering, University of Aveiro, Aveiro, Portugal

Aníbal Costa PhD

Full Professor, Department of Civil Engineering, University of Aveiro, Aveiro, Portugal

The aim of this work was to study the behaviour of existing timber trusses in order to improve the knowledge that may support engineers in the definition of more adequate restoration interventions in old buildings, particularly of long-span timber structures, as industrial or monumental constructions. For this purpose, a cyclic load-carrying test was carried out on a full-scale timber planar truss rescued from an old industrial roof structure. Before the tests, an accurate geometrical characterisation was performed and the biological condition of the timber elements was evaluated by non-destructive tests to determine their effective cross-section. The results of the destructive loadcarrying test were used to calibrate a numerical model with the aim of assessing the effect of the effective crosssections of the truss components and the axial stiffness of the joints on the overall response observed during loading. The full-scale test performed proved the importance of this type of testing in assessing the behaviour of existing timber trusses. It is essential to assess the damage of the joints and to model correctly their behaviour so as to numerically reproduce the overall behaviour of timber trusses.

\begin{tabular}{|c|c|}
\hline$A_{\text {heel strap }}$ & cross-sectional area of heel strap \\
\hline$E_{\text {steel }}$ & modulus of elasticity of steel \\
\hline$E_{\alpha}$ & $\begin{array}{l}\text { wood elastic modulus in direction forming an angle } \\
\alpha \text { with the fibre }\end{array}$ \\
\hline$E_{0}$ & modulus of elasticity in direction along fibres \\
\hline$E_{90}$ & $\begin{array}{l}\text { modulus of elasticity in orthogonal direction of } \\
\text { fibres }\end{array}$ \\
\hline$G$ & shear modulus \\
\hline$k_{\mathrm{ax}}$ & axial stiffness of joints \\
\hline$k_{\mathrm{ax}, \mathrm{hs}}$ & axial stiffness of tie beam-post connections \\
\hline$L$ & longitudinal direction \\
\hline$L$ & $\begin{array}{l}\text { nominal notch length, where compression } \\
\text { deformation occurred }\end{array}$ \\
\hline$l_{\text {heel strap }}$ & length of heel strap \\
\hline$R$ & radial direction \\
\hline$S$ & nominal notch area \\
\hline$T$ & transversal direction \\
\hline$\delta$ & maximum vertical displacement of truss \\
\hline$v$ & Poisson ratio \\
\hline
\end{tabular}

\section{Introduction}

The assessment of existing timber structures requires, and relies upon, the determination of the mechanical properties of the individual timber members, as well as the behaviour of joints and structural system effects (Cruz et al., 2015; Dietsch and Kreuzinger, 2011; Frühwald, 2011; Uzielli, 2004).
In existing timber structures, the first step in safety assessment is evaluation of the actual mechanical properties of the material (Riggio et al., 2013). Despite significant effort in the development of non-destructive testing, the strength of timber members can only be rigorously determined by destructive tests, which is often unacceptable in the case of historic buildings and other existing timber structures (Calderoni et al., 2010; Kasal, 2010).

In practice, it is the lack of knowledge about the mechanical properties of these materials and their structural behaviour that normally leads to the replacement of existing wooden structures, instead of their retrofitting, to comply with the safety and serviceability requirements proposed in recent codes and recommendations. Moreover, inaccurate characterisation of the behaviour of traditional timber roof structures can result in adverse stress distribution estimates in the members, as a result of inappropriate strengthening adopted in joints, in terms of stiffness and/or strength (Descamps et al., 2014; Drdácký et al., 1999). Thus, laboratory tests on scaled or fullscale specimens of members, connections and trusses are recognised as instruments that can provide valuable information for a better understanding of the behaviour of traditional timber roof structures (Bertolini-Cestari et al., 2013; Del Senno and Piazza, 2003).

Portuguese traditional buildings are normally constituted by timber roof systems, with the truss as the main structural 
system for larger spans. Nowadays, a considerable number of timber roofs require structural intervention as a consequence of natural degradation of the material, improper maintenance of the wood or of the structure itself, faulty design or construction, or accidental actions. A precise assessment of the extent of degradation and its effects in the overall structural system should precede any retrofitting action, which can vary from simple works in the covering system to substitution of structural members or strengthening of joints/elements.

The assessed truss was saved from the roof structure of an old factory which was demolished in Avanca, Portugal. The truss was transported as a whole to the laboratory in spite of the difficulties involved. The option of transporting the truss in parts was ruled out because the state of degradation of the wooden members would have hindered the reassembling of the truss.

The roof was covered by ceramic tiles and its free span was $12.7 \mathrm{~m}$ with a slope of $26^{\circ}$. The main structure was composed of 13 similar Howe trusses made of maritime pine (Pinus pinaster, Ait.) with an average spacing of $3.5 \mathrm{~m}$. In Figure 1, the assessed Howe timber truss is presented along with the average cross-section of each element and details of the main carpentry joints. The actual age of the truss structure is not precisely known, but the factory has been known to exist since 1920 (Santos, 2009).

\section{Visual inspection}

A detailed visual inspection should be the starting point for any analysis of traditional timber structures. The visual inspection enables detection of external wood decay, as well as any visible mechanical damage. Moreover, it can be used to detect adverse climatic conditions in the past or present, as evidenced by moisture stains on exposed surfaces (Branco et al., 2010).

The visual inspection undertaken for the studied truss comprehended its geometric assessment and the state of conservation. A detailed inspection of each truss component was performed, while the dimensions of representative cross-sections of each element were measured.

During the visual inspection, it was evident that one side of the truss presented a more pronounced degradation. This is mainly a consequence of the cutting process of the timber elements that compose the truss. In fact, all of the timber elements present an eccentricity of the pith in relation to the cross-section, resulting in different durability of the timber element faces. According to EN 350-2 (CEN, 1994) and FICHA M2 (1997), this wood species is moderately to slightly resistant to fungi but susceptible to beetles, termites and marine borers, with the heartwood being extremely difficult to treat, whereas the sapwood is easy to treat. However, for the service class corresponding to an industrial roof under cover and not exposed to the weather, practice shows that, in the
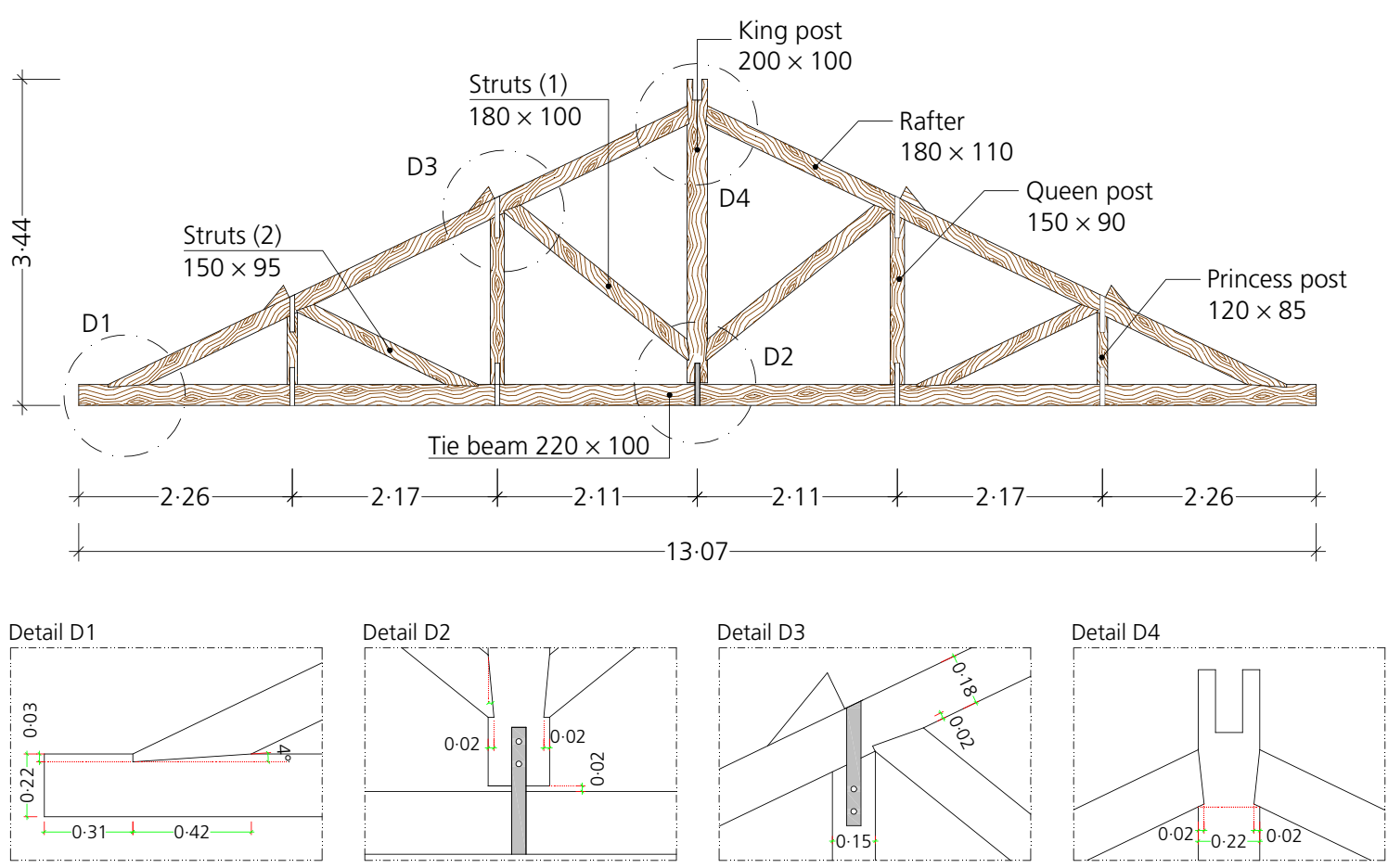

Figure 1. Timber truss studied (dimensions in metres and crosssections in millimetres) 
Structures and Buildings

Volume 169 Issue SB5
Load-carrying capacity test of a long-span

timber truss

Branco, Varum, Ramisote and Costa case of the maritime pine (Pinus pinaster, Ait.), the heartwood can be assumed to be durable to biological and insect attacks, whereas the sapwood is not (FICHA M2, 1997). Figure 2 shows examples of cross-sections where the eccentricity of the pith is visible and the degradation is concentrated in the sapwood.

Visual inspection was also fundamental to perform a detailed geometric assessment of the various components of the truss, including the joints. In terms of joints, all are carpentry joints without tenons or pegs and most of them have a single step (notch). The ones that can be subjected to tension, namely, the joints of the posts with the tie beam and rafters, additionally have steel plates (stirrups) $5 \mathrm{~mm}$ thick and $25 \mathrm{~mm}$ wide, nailed with square nails of $4 \mathrm{~mm}$ dia. spaced $50 \mathrm{~mm}$ apart (see Figure 1). During the preparation of the truss for testing and the transportation as a single piece to the laboratory, some joints developed gaps of significant size that were filled with wood in the case of compressed joints (Figures 3(a) and 3(b)). On the contrary, the separation between the king post and the tie beam was restored by cutting the king post by $20 \mathrm{~mm}$ along its length (Figure 3(c)). Moreover, one
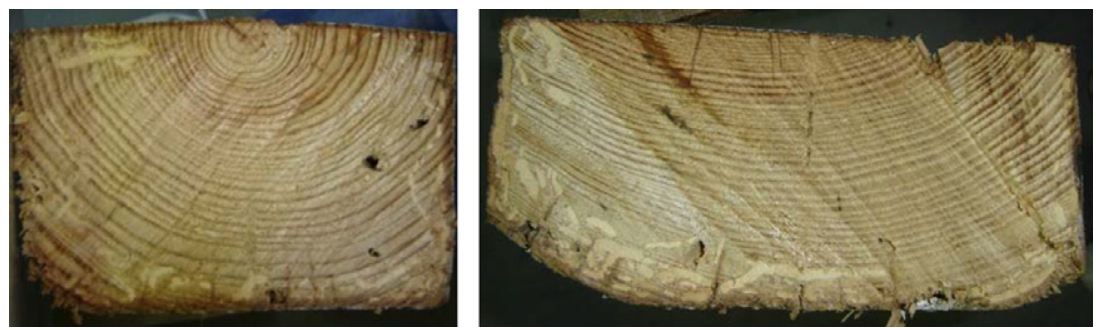

Figure 2. Examples of cross-sections of the timber elements evidencing the eccentricity of the pith and the concentration of degradation in the sapwood

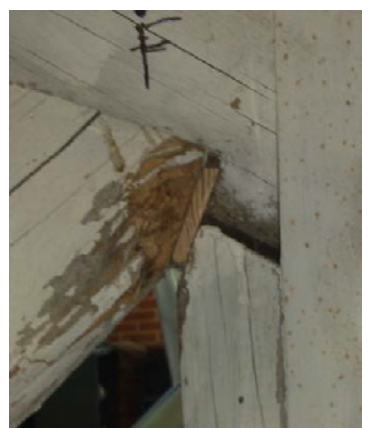

(a)

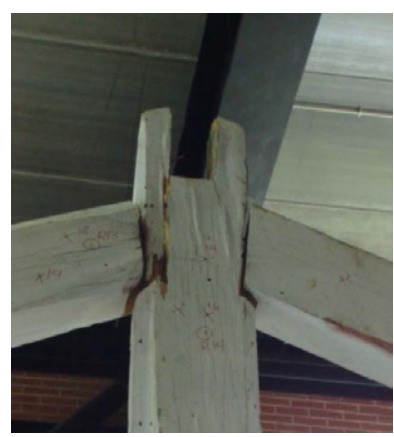

(d)

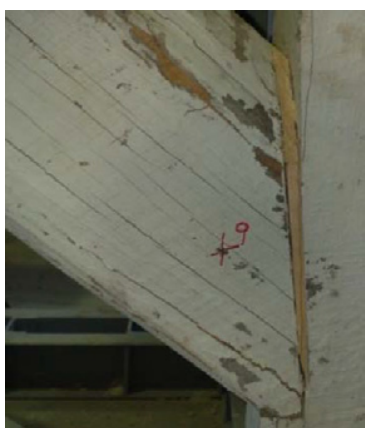

(b)

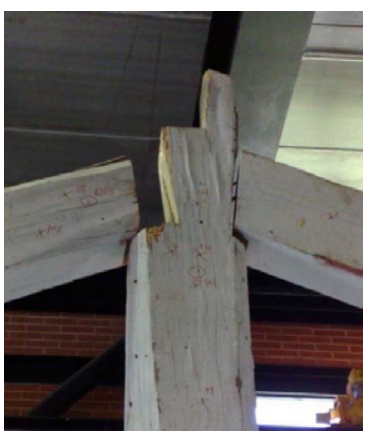

(e)

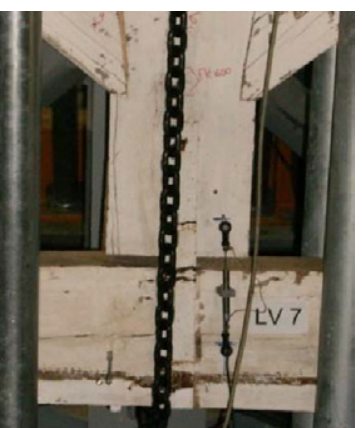

(c)

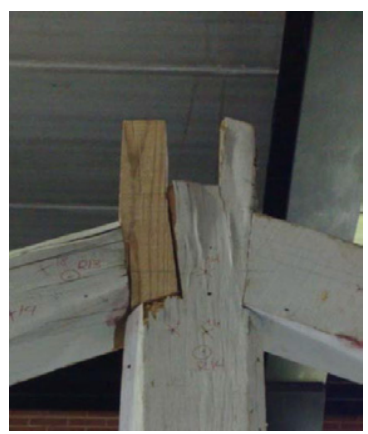

(f)
Figure 3. Reparation of some joints: (a) filling the gap with wood in a strut-rafter joint; (b) restoring the contact between connected surfaces in a strut-king post joint; (c) ensuring the separation between the king post and the tie beam; (d) decayed end part of king post; (e) removal of decayed part of king post;

(f) replacement of decayed part of king post by new piece 
joint between the king post and one rafter was partially rebuilt as a result of degradation in the king post. The decayed part was replaced by a piece of the same wood species (Figures 3(d)-3(f)).

Visual inspection also allowed the abnormalities of the material to be identified - wane, twist, bow and grain slope and the geometry of the truss - gaps in the joints, out-of-plane deformations of the elements and inappropriate contact between the king post and the tie-beam. However, the main damage observed was the biological deterioration of timber caused by insects, which although mostly superficial (Figure 4), differed in the extent of damage (in depth) in the truss elements. From the visual inspection, a map of the damage distribution was produced, identifying and locating abnormalities and superficial deterioration (Figure 5). This map proved to be fundamental to plan and choose the type of non-destructive tests (NDTs) and where they would be carried out. These tests were conducted during the second phase, in order to evaluate the condition of the timber components of the truss, beyond the superficial damage assessed through the visual inspection.

\section{Non-destructive tests}

After the visual inspection, and based on the damage map produced, a series of non-destructive tests was planned, aiming to characterise the extent of damage in order to assess the effective cross-section of each truss component. For this reason, two local non-destructive tests were applied: Pilodyn ${ }^{\circledR}$ and Resistograph ${ }^{\circledR}$. While the visual inspection pointed out the superficial deterioration of timber, the Pilodyn, a hardness test, measured the extent of degradation. In fact, the effects of degradation through the thickness of a timber element cannot be fully assessed by visual inspection or superficial tests. The Resistograph test method allows the timber resistance profile to be measured, drilling along the depth of the element, thereby detecting voids or defects inside the member. Since the results of both non-destructive tests are influenced by the presence of water, the moisture content of each component of the timber truss was measured, and the results obtained are presented in Table 1. Moisture content was measured using a hygrometer following the measuring scheme and procedure outlined in UNI 11035-1 (UNI, 2003). The values measured were within the range $11 \cdot 1-14 \cdot 3 \%$, with a mean value of $12 \cdot 5 \%$ and associated coefficient of variation $(\mathrm{CoV})$ of $6 \%$.
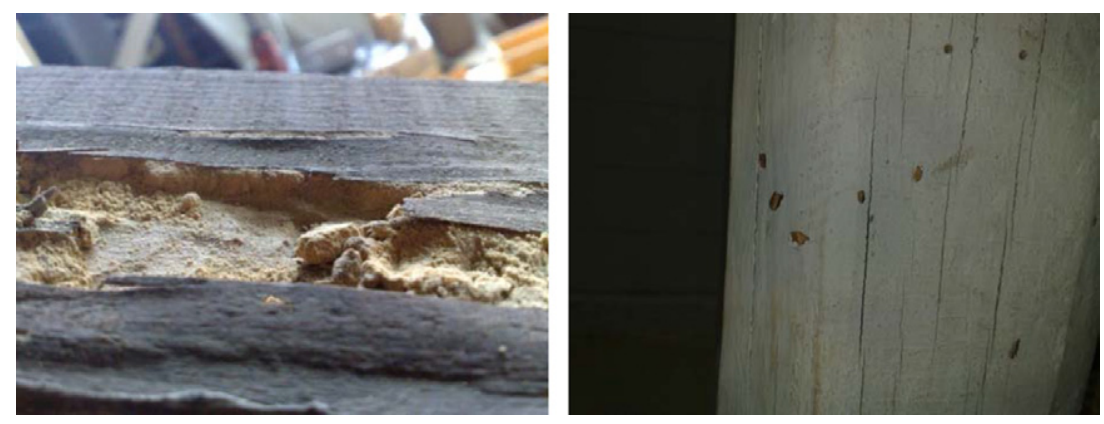

Figure 4. Superficial biological deterioration of timber caused by insects

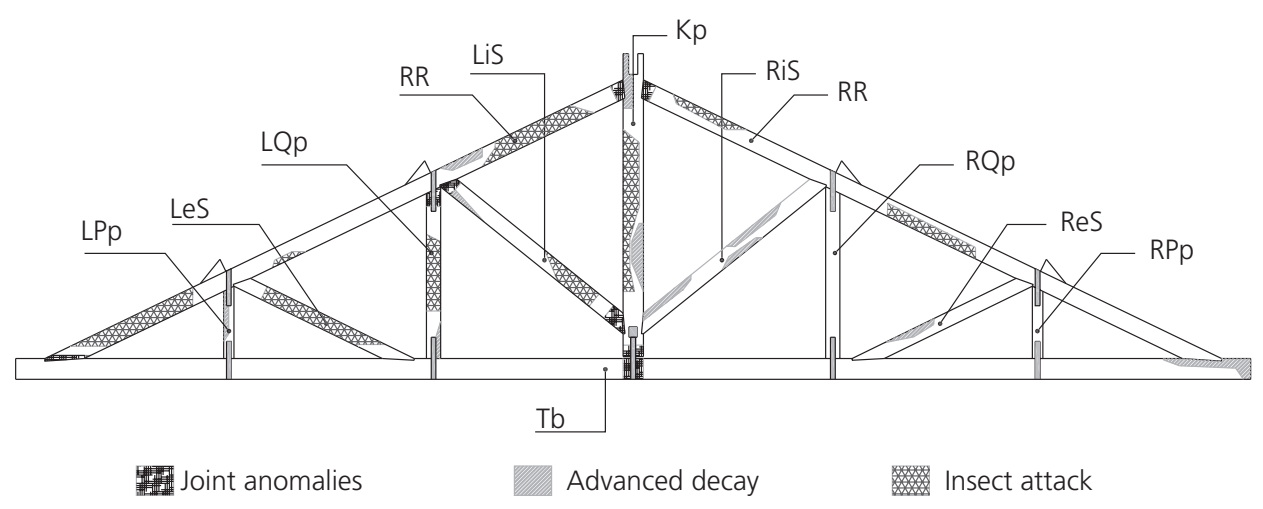

Figure 5. Map of damage detected in the truss by visual inspection 
Element

Moisture content: \%

\begin{tabular}{ll}
\hline Tie beam (Tb) & $14 \cdot 3$ \\
King post (Kp) & $12 \cdot 1$ \\
Left queen post (LQp) & $11 \cdot 1$ \\
Right queen post (RQp) & $11 \cdot 5$ \\
Left princess post (LPp) & $12 \cdot 2$ \\
Right princess post (RPp) & $12 \cdot 3$ \\
Left interior strut (LiS) & $13 \cdot 1$ \\
Right interior strut (RiS) & $12 \cdot 2$ \\
Left exterior strut (LeS) & $12 \cdot 6$ \\
Right exterior strut (ReS) & $12 \cdot 9$ \\
Left rafter (LR) & $12 \cdot 6$ \\
Right rafter (RR) & $12 \cdot 5$
\end{tabular}

Table 1. Moisture content of each component of the truss

\subsection{Pilodyn}

Pilodyn is a non-destructive test that evaluates the superficial state of a wood structural member (superficial density, resistance and decay) through a penetration depth parameter. Pilodyn measurements can be used for the estimation of parameters such as density, mechanical properties and degradation. Unfortunately, in the case of decayed or damaged timber, the method encounters limitations associated with its superficial assessment essence.

The principle of operation is based on penetration (maximum of $40 \mathrm{~mm}$ ) of a pin (diameter of $2.5 \mathrm{~mm}$ ) in the wood element by means of a dynamic impact. The test output is the penetration depth.

Owing to the superficial nature of the test, the use of Pilodyn test results for the estimation of mechanical properties, should be used in combination with visual inspection (Branco et al., 2010). In this case study, Pilodyn was used to assess the extent of the superficial deterioration of each timber element of the truss. By comparing the penetration depth measured in the non-deteriorated wood with the values in deteriorated zones, the extent of degradation is quantified and, therefore, the effective cross-section can also be quantified. To systematise the results of the analysis, each timber element was divided into segments $40 \mathrm{~cm}$ long. For each segment and for each side of the element, the mean value of the penetration depth was calculated as the average of three measurements. As an example, in Figure 6, the distribution of the penetration depth values obtained in the north side has been plotted, with the more deteriorated portions corresponding to the sapwood.

\subsection{Resistograph}

The use of a small-diameter needle-like drill was introduced by Rinn (1992). The cutting resistance of a needle is recorded as a function of depth as the needle penetrates the timber. The resulting profile can be used to determine the location and extent of voids in the timber and/or variation in density. This technique is highly effective for quantifying the extent of deterioration in timber.

In total, 26 Resistograph tests were performed on the truss under study, evaluating the depth of deterioration in representative points previously identified, based on the Pilodyn penetration depth results, and assessing the internal projection of anomalies visible from the exterior (Figure 7).

Two examples of graphs obtained with the Resistograph are presented in Figure 8. Figure 8(a) presents the identification of the extent of the internal deterioration and Figure 8(b) shows the assessment of a ring shake, in two different sections. It is important to point out that the Resistograph tests have only detected one section with an internal defect, namely, the one identified as R10.

\section{Load-carrying test}

After the assessment of the timber truss condition, a quasistatic cyclic test was performed to evaluate its load-carrying capacity. The test set-up reproduces the in-service load distribution applied on the truss, through five point loads representing the ridge and four purlins, simulating the points where the

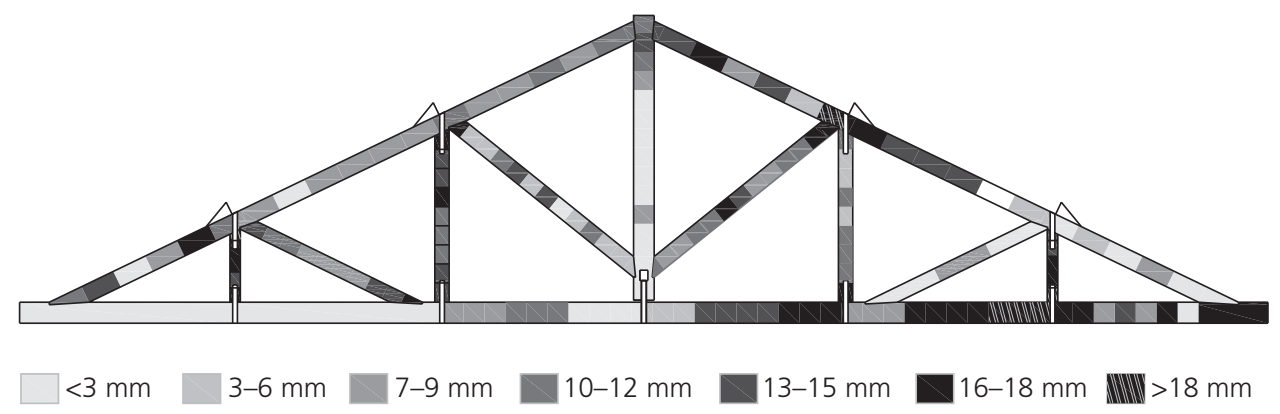

Figure 6. Penetration depth results obtained with the Pilodyn test (north side) 


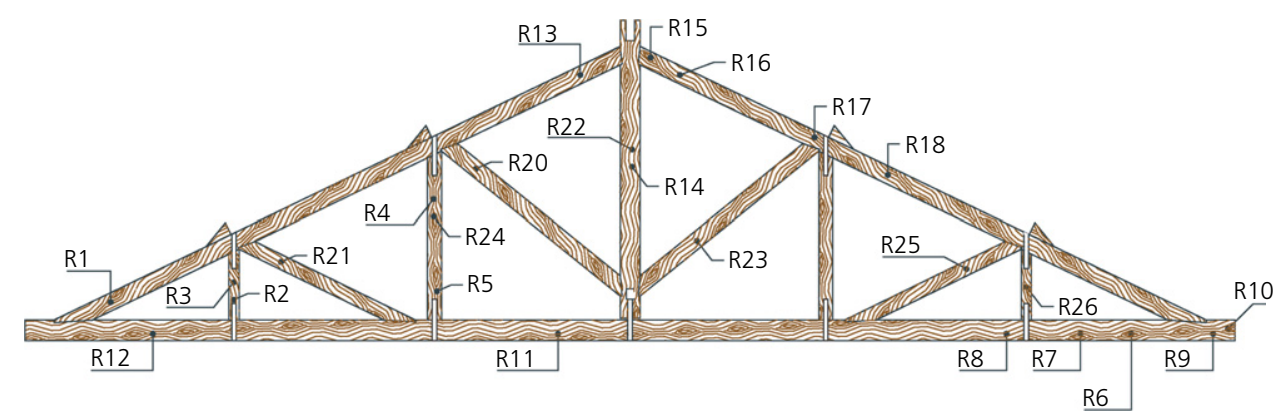

Figure 7. Identification and location of the Resistograph tests performed

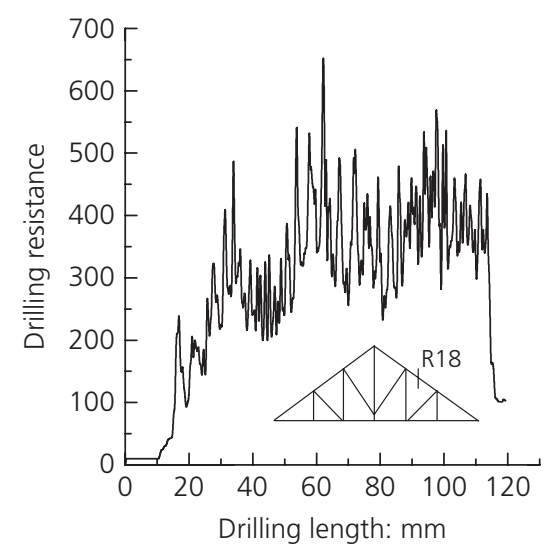

(a)

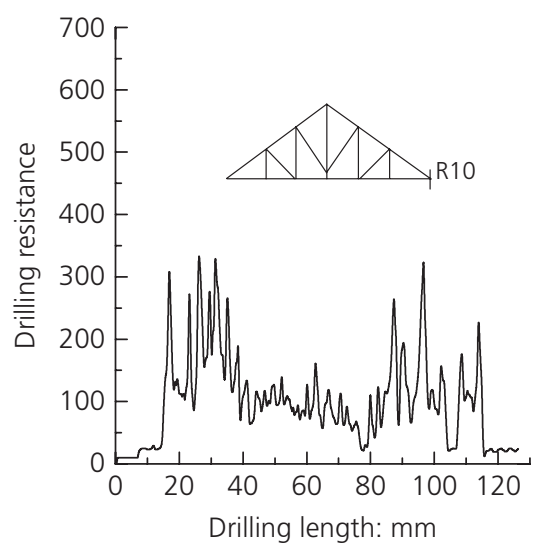

(b)

Figure 8. Examples of the results obtained with the Resistograph: (a) test R18, superficial deterioration; (b) test R10, cross-section with a ring shake

roof structure would settle. Those loads have been applied through five hydraulic actuators, fixed to the reaction floor of the civil engineering laboratory of the University of Aveiro. Each actuator was linked to a chain embracing the rafter of the truss at each loading point (Figure 9). To guarantee the contact between all components of the truss, carpentry works were developed before testing, such as filling gaps and substituting decayed wood near the joints (Figure 10). To ensure the lateral stability of the truss during the in-plane loading test, a lateral bracing system consisting of steel tubes was built to avoid out-of-plane movements, as shown in Figure 11.

\subsection{Load procedure}

The load-carrying test that was performed consisted of a symmetrical quasi-static cyclic (loading and unloading) test with cycles of increasing amplitude until the truss failure. The load cycles were performed with an increase in amplitude of $10 \mathrm{kN}$ from cycle to cycle. In each cycle, after the peak load value was attained, the unloading was done until approximately
$10 \mathrm{kN}$ at each loading point, preventing the opening of the joint connections. A symmetrical load pattern was applied to simplify the loading procedure, despite the fact that nonsymmetrical loads can be more demanding. However, the behaviour of the wooden truss structures can be characterised under symmetric loading conditions and, in this test, the symmetric load distribution led to a non-symmetric response (Branco et al., 2010). Figure 12 presents the loading history (total load applied in each loading step) imposed by all hydraulic jacks during the test, up to a total of nine cycles, when failure occurred.

\subsection{Instrumentation}

Eighteen transducers were used to measure relative displacements during the load-carrying test, at the locations seen in Figure 13. Eleven wire potentiometers (denoted LF) were used to measure the absolute displacement of points of the structure and seven linear variable differential transducers (LVDTs, denoted as LV here) were used to measure the relative 

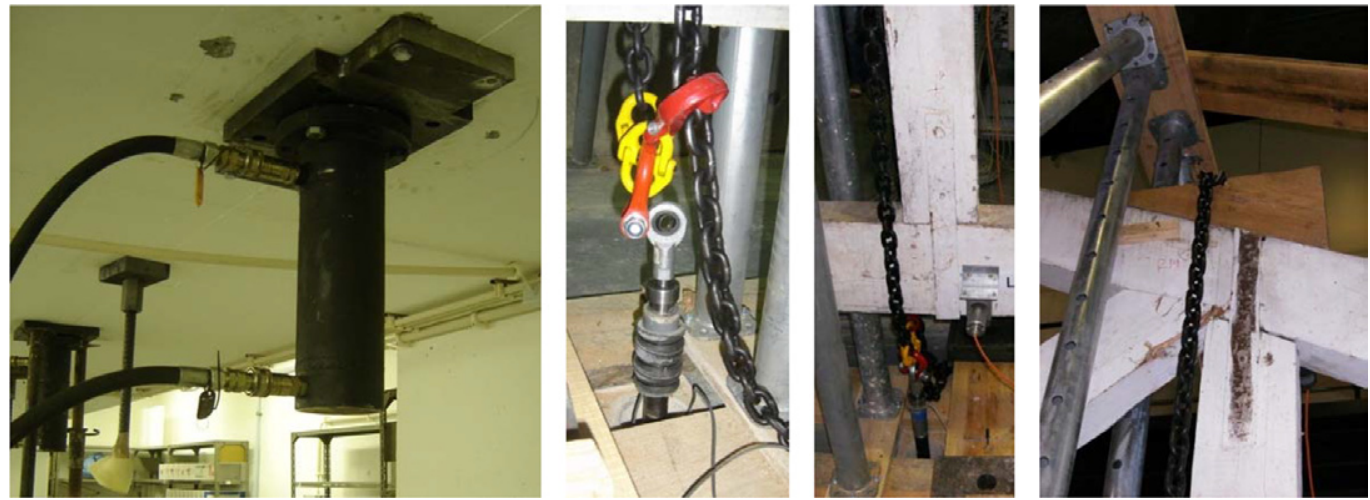

Figure 9. Details of the testing set-up: hydraulic jack and chain system for load application
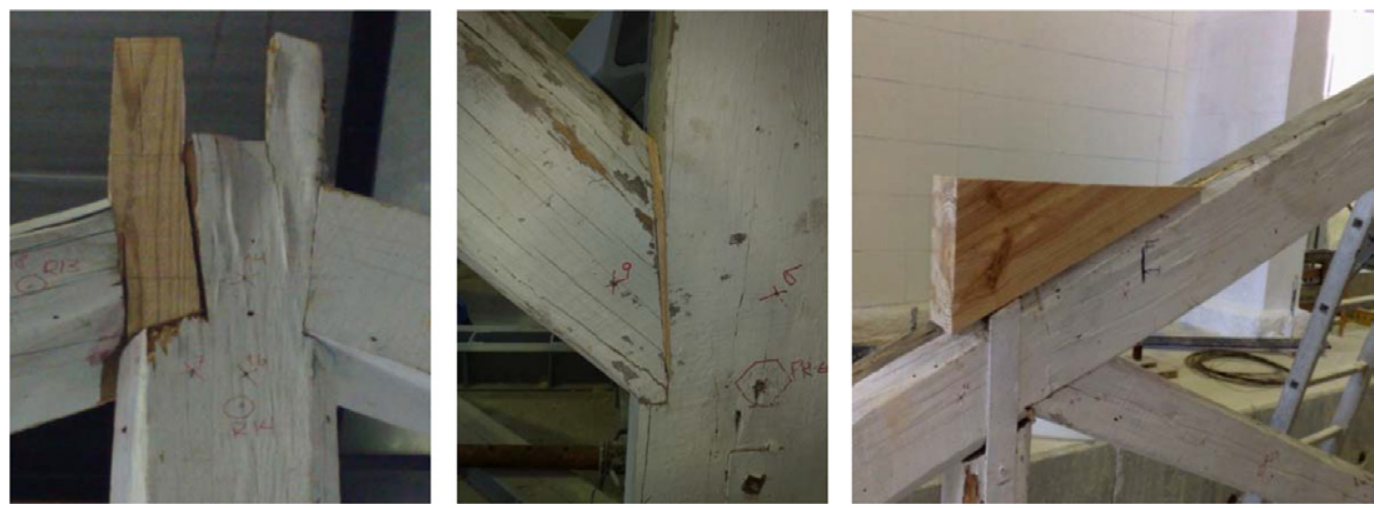

Figure 10. Carpentry works carried out to ensure a correct execution of the load-carrying test

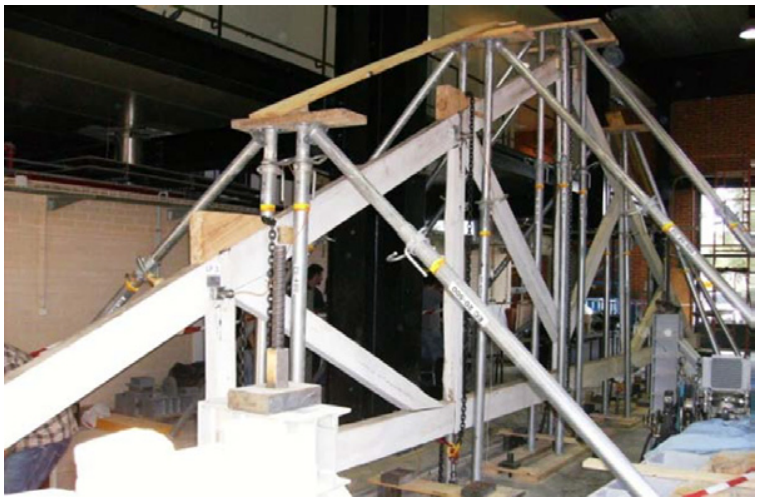

Figure 11. Lateral bracing system implemented

displacements between different elements of the truss. The relative rotation of the rafter-tie beam joints was calculated based on the values registered by two pairs of sensors, LV2-LV3 and

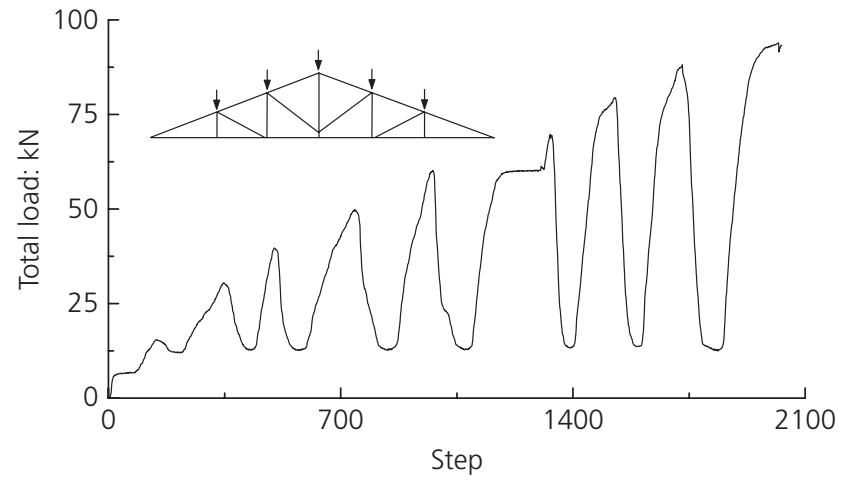

Figure 12. Loading history adopted in load-carrying test (total load applied in each loading step)

LV10-LV11. Signals were recorded using a National Instruments DAQ device with 24 channels controlled by LabView (Arêde et al., 2004). 

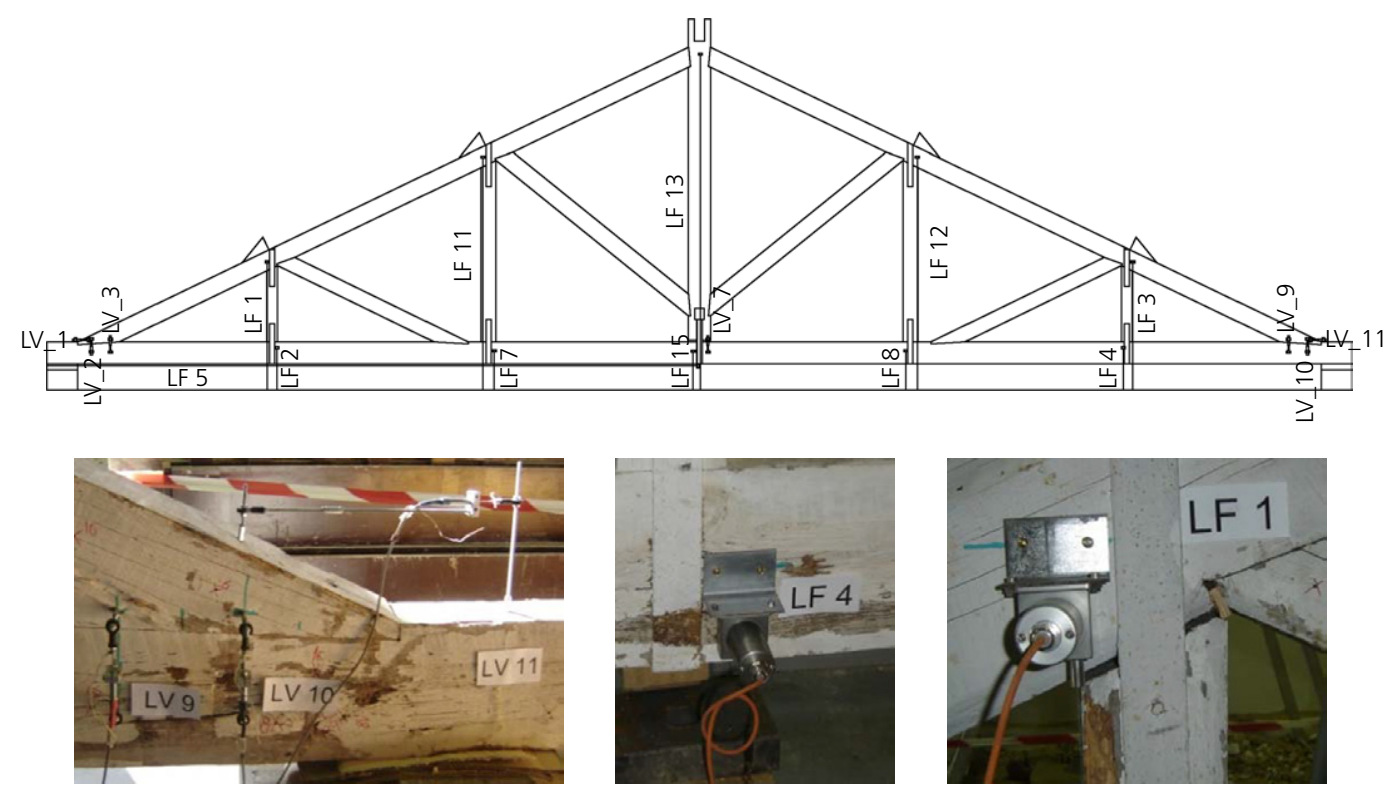

Figure 13. Instrumentation layout and details

\subsection{Truss response during the load-carrying test}

Timber structural elements normally have an elastic response when loaded. However, the response of truss structures under the cyclic loads may be highly non-linear (Branco et al., 2008, 2010). The unloading branch of each cycle normally presents residual, unrecoverable deformations (as represented in the example of Figure 14). During the first loading cycle, the most important adjustments of the truss elements take place, with closing of the gaps in the joints. Moreover, the type of connection (local embedment) of wooden elements, associated with the superficial degradation of the contact surfaces between elements, plays a key role in the non-linear response of the truss structures. This local non-linear behaviour is observable in the unrecoverable rotation suffered by the rafter-tie beam joints after each loading-unloading cycle (Figure 15).

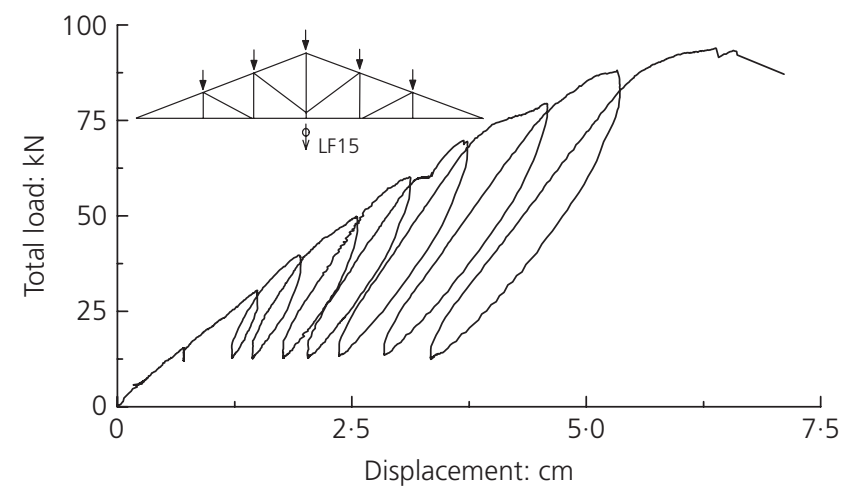

Figure 14. Experimental load against displacement graph at LF15
The combined effect of the local material degradation and the joint slip is observed in Figure 16. The slippage of the rafter relative to the tie beam was monitored by a LVDT placed at the top of the rafter-tie beam joints.

The force-displacement response measured at the left joint (Figure 16) shows a slip due to the crushing of wood in the rafter and tie beam. At the right joint (Figure 16), the slip measured is essentially due to the splitting of the tie-beam fibres (failure by shear parallel to the grain) in the final load cycle, while during most of the loading procedure the slip measured (by wood crushing) is less than that corresponding to the left joint. This shear damage observed is justified by the different degradation state of each of the connections. Moreover, on the right side of the tie beam, the shake ring defect, namely the internal fissures between the annual rings,

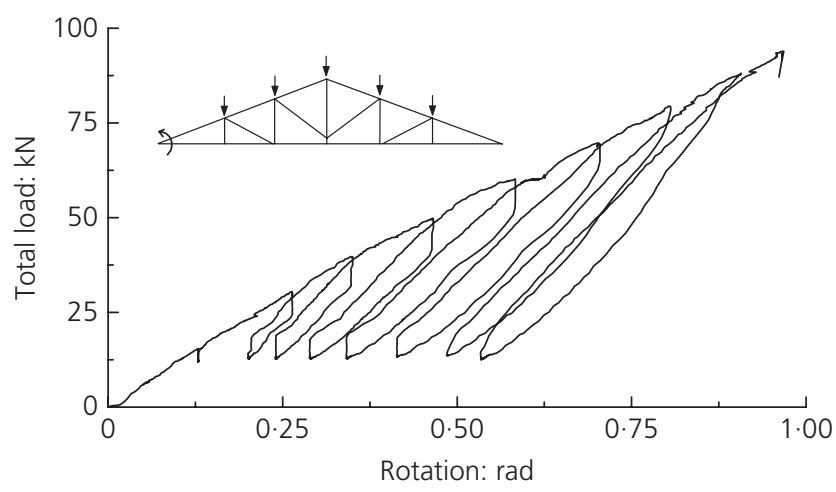

Figure 15. Relative rotation of the left rafter-tie beam joint 


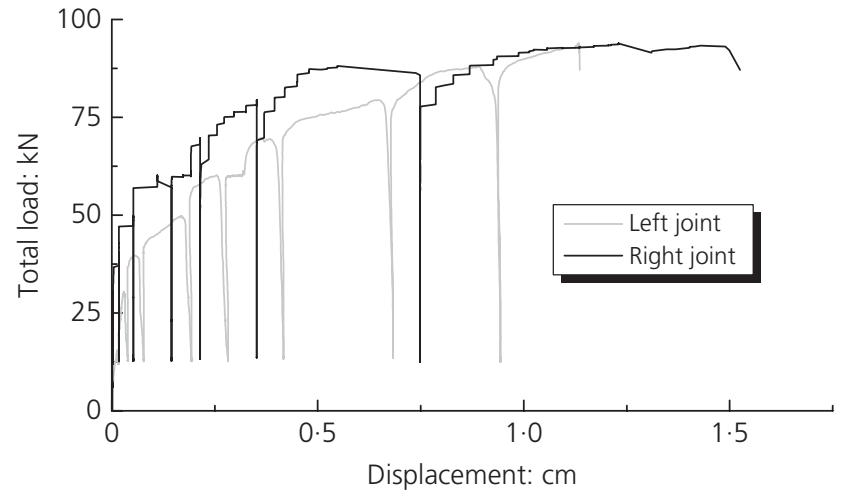

Figure 16. Slippage (horizontal displacement) measured at the rafter-tie beam joints

significantly reduced the shear strength of that section. This faulty behaviour of the right joint of the tie beam-rafter explains the smaller relative rotation measured in this joint during the load-carrying test in comparison with the left joint (Figure 17).

The load was applied with an approximately symmetric distribution, with small differences, as is acceptable in tests of this complexity and scale. Despite the symmetric load distribution, the truss tie beam presented a non-symmetric vertical deformation with a maximum value of $6.7 \mathrm{~cm}$ at LF8. Instrumented points LF7, LF15 and LF8 registered similar values for the displacement, whereas LF4 measured a vertical displacement which was $24 \%$ higher than the corresponding value in LF2. Figure 18 presents the vertical displacement of the truss tie beam measured during the load-carrying test.

The connection between the tie beam and the king post, made by a metal plate embracing the tie beam, worked properly during the entire cyclic loading test. This joint worked as a vertical support of the tie beam, preventing vertical displacement,

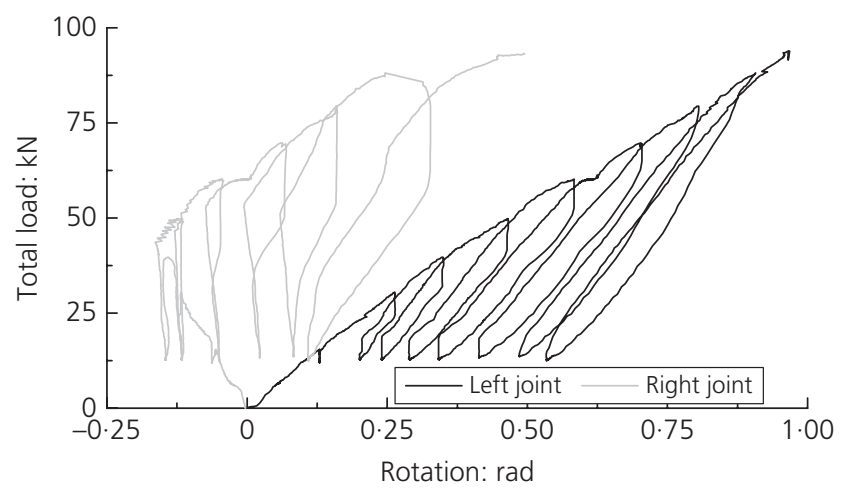

Figure 17. Relative rotation of the rafter-tie beam joints

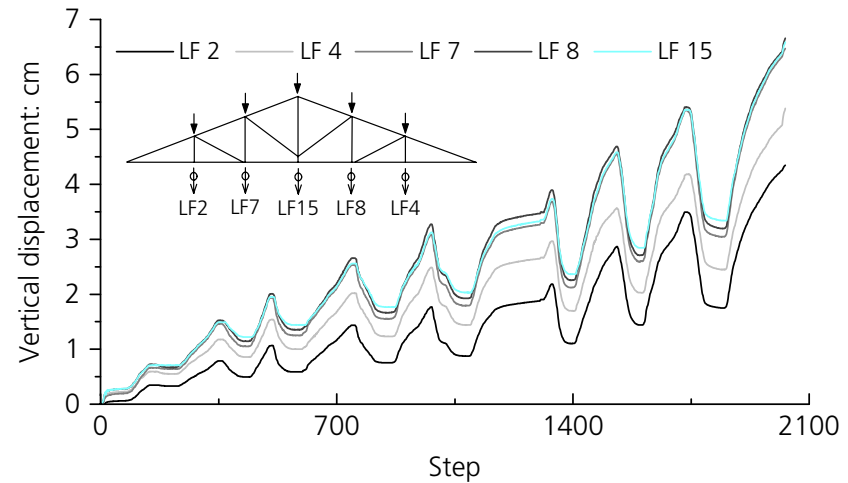

Figure 18. Evolution of vertical displacements of truss tie beam registered during load-carrying test

but allowing the connection to close, or in other words, it did not curtail the movement of the king post towards the tie beam (Figure 19). This analysis also clearly demonstrated the non-linear response of the truss with unrecoverable permanent deformations, associated with the behaviour of the joints.

By subtracting the vertical displacements of the tie beam from the values measured by the instruments located at both rafters, it is possible to assess the behaviour of the joints between the other posts and the tie beam. Figure 20 depicts the response of the joints between the tie beam and the queen post and princess post, assuming that positive values correspond to a closing movement of the joint. Joints between the tie beam and the queen posts (LF7 and LF8) behave elastically in both directions, that is, they open and close as the load increases and decreases, respectively. The joint between the tie beam and the left princess post (LF2) presented a constant closing movement with very small opening movements during unloading. However, the right joint between the tie beam and the princess post (LF4) showed a non-linear response with unrecoverable deformation towards closing.

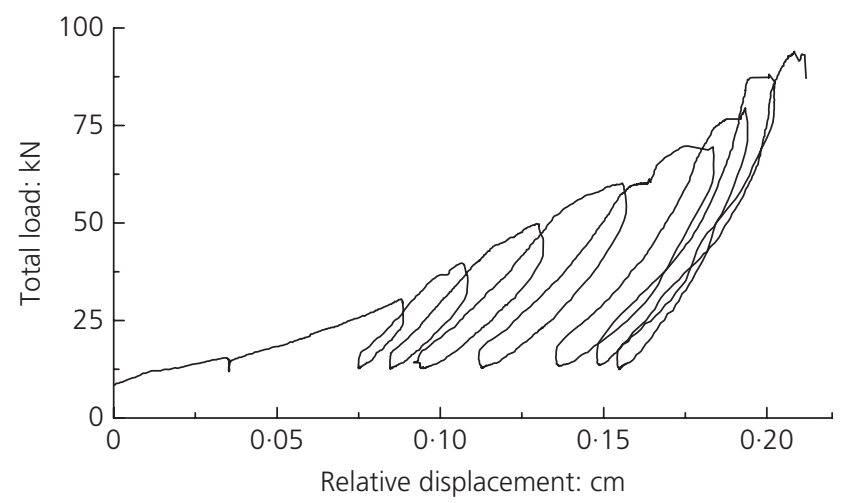

Figure 19. Relative displacement between tie beam and king post 


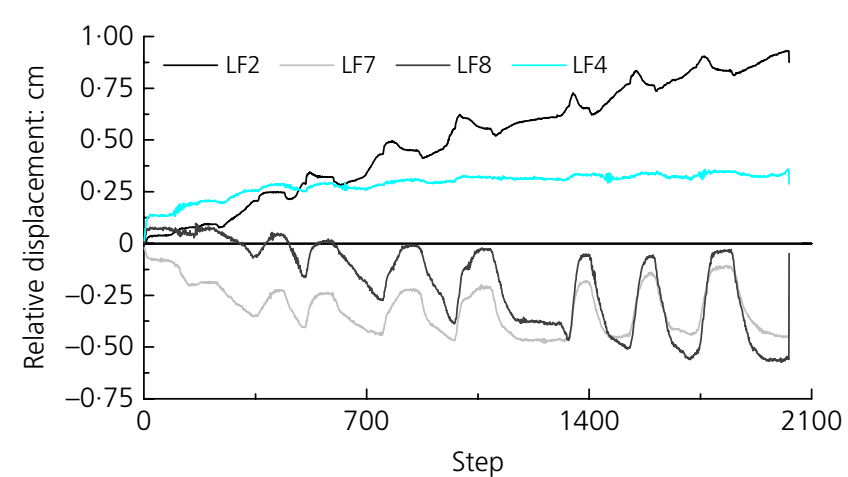

Figure 20. Response of joints between tie beam and posts

The response of the joint between the king post and the tie beam can be assessed in two ways: subtracting the vertical displacement measured in LF15 from that in LF13 or analysing the measurements registered by LV7 (see Figure 13). Despite the differences in both measurements, the behaviour displayed is similar (Figure 21). This joint presents an elasto-plastic

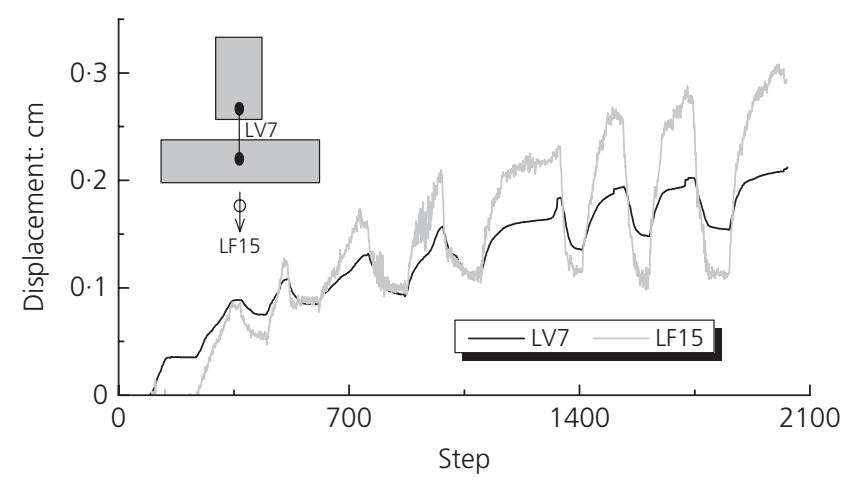

Figure 21. Response of joints between tie beam and king-post

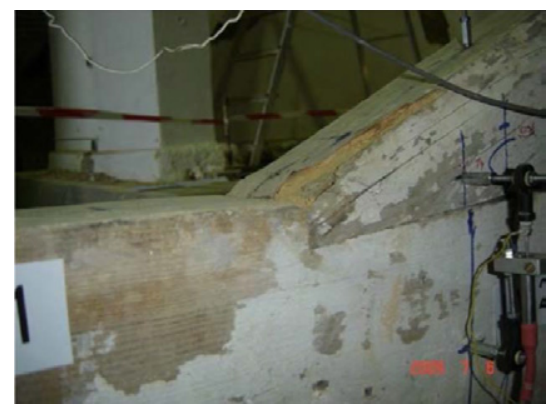

(a)

Figure 22. Evolution of wood local embedment in left rafter-tie beam joint: (a) fifth load cycle $(60 \mathrm{kN})$; (b) seventh load cycle $(80 \mathrm{kN})$ response, with an unrecoverable closing movement as the load applied increases with an elastic branch $(\approx 0 \cdot 1 \mathrm{~cm})$ which is recovered during unloading.

\subsection{Damage evolution and failure mechanism}

During the first loading cycle, no damage was observed. In the fifth load cycle, for a load of $60 \mathrm{kN}$, the local embedment of the wood in the left rafter-tie beam joint became visible due to the large displacements (Figure 22(a)). In the two subsequent loading cycles, with peak load values of $70 \mathrm{kN}$ and $80 \mathrm{kN}$ respectively, wood local embedment appeared on the right rafter-tie beam joint while, in the left joint, this damage was further developed (Figure 22(b)).

In the eighth loading cycle, for a load value of $85 \mathrm{kN}$, shear failure parallel to the grain was observed on the right rafter-tie beam (Figure 23(a)), based on the ring shake detected in the diagnosis phase (Figure 23(b)). Finally, in the ninth load cycle, for a load value of $95 \mathrm{kN}$, a complete shear failure mechanism, parallel to the grain, occurred (Figure 23(c)). The slip magnitude in this joint led to a subsequent tension failure (disconnection) in the exterior joint of the strut-tie beam (Figure 24).

\subsection{Influence of the joints' behaviour in the overall response}

The behaviour of the joints had a clear influence on the overall response of the truss. It was found that the natural defect (ring shake) present in the right rafter-tie beam joint led to the local failure mechanism and rupture of the truss. On the other hand, the joints played an important role in the deformation of the truss during the load-carrying test performed. The unrecoverable deformation observed after the first cycles (see Figure 14) results directly from the existence of gaps in the joints, despite the carpentry works of consolidation that were made (see Figure 3). But even after the gaps in the joints have been theoretically removed, the behaviour of the joints conditioned the overall deformation of the truss. In particular, the

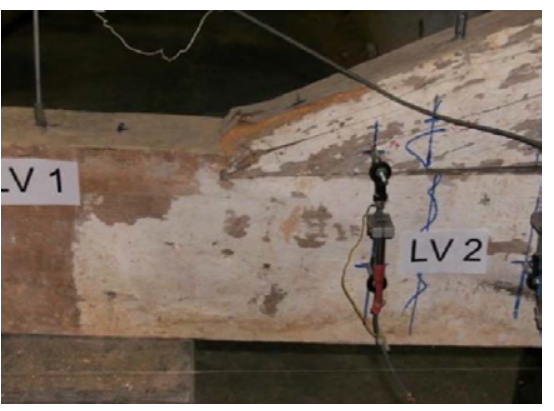

(b) 


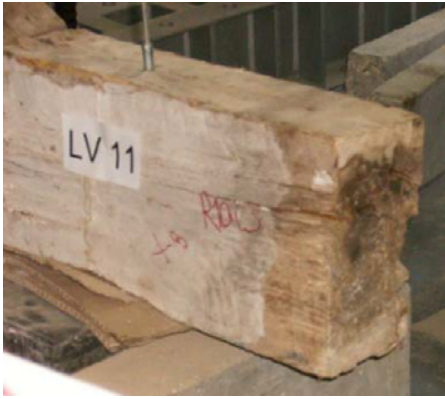

(a)

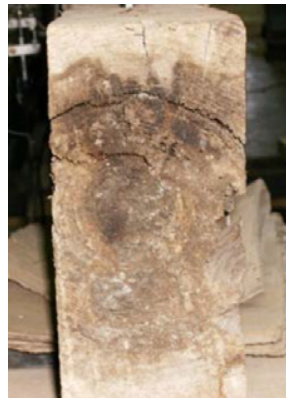

(b)

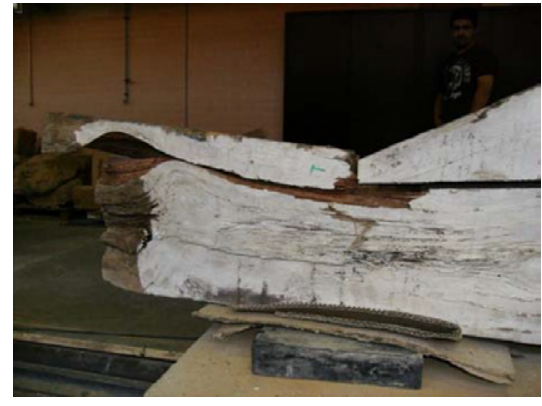

(c)

Figure 23. Shear failure parallel to grain caused by a ring shake: (a) beginning of shear failure; (b) ring shake; (c) final position of right rafter-tie beam joint

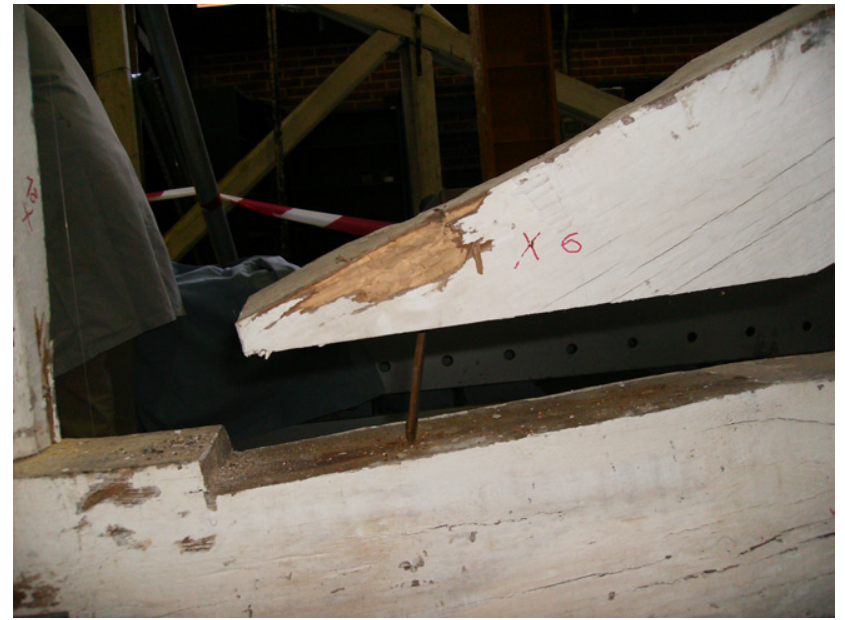

Figure 24. Opening of right strut-tie beam joint

slip (horizontal movement of the rafter) observed in the raftertie beam joints (see Figure 16) affects the overall deformation of the truss. With the slip in those joints, the entire superior part of the truss (above the tie beam) moved down (proved by the closing movement observed in the joints between the posts and the tie beam, see Figure 20), pushing the tie beam down and leading to an increase in the truss deformation. Moreover, this slip movement, which was more pronounced in the right rafter-tie beam joint, limited the capacity of those joints to rotate (see Figure 17).

\section{Numerical modelling}

The structural analysis program SAP2000 (SAP, 2000, v9.0.3) has been used to model the tested structure. A model has been developed adopting beam elements with variable dimensions, and semi-rigid joints to simulate the connections between the different elements. A linear behaviour is assumed for the material model.

\subsection{Material model}

Timber is taken to be an orthotropic material with anatomic cylindrical coordinates corresponding to the longitudinal, $L$, radial, $R$, and transversal, $T$, directions of the tree trunk. According to Mackerle (2005) and Parisi and Piazza (2000), the cylindrical coordinates may be approximated as orthogonal for the material extracted from the outer region of the trunk. In this case, the elastic moduli for an asymmetric model, are $E_{0}$ in the direction along the fibres, and $E_{90}$ orthogonal to it, plus a shear modulus, $G$, and a Poisson ratio, $v$. In the absence of mechanical characterisation tests, the values for the material properties were taken from Ficha M2 (1997), which defines the strength classes and the corresponding characteristic values for Portuguese maritime pine.

\subsection{Geometric and mechanical models}

The geometry and loads on the truss permit the assumption of a plane stress model. The truss is analysed as a frame structure, assuming elastic behaviour for the members, while joints are modelled using non-linear link elements (Nlink). The choice for the joints is justified by the ability of the link element to simulate the semi-rigid behaviour characteristics of traditional timber connections (Parisi and Piazza, 2000; Piazza et al., 2004). Moreover, those elements can also be used to simulate both extreme conditions, that is, perfect hinges or rigid joints.

The timber members of the truss are modelled as beam elements with the cross-sections defined based on the dimensions obtained in the diagnosis phase, as reported in Section 2. Therefore, in the model, each member was simulated by adopting $40 \mathrm{~cm}$ length elements with the cross-section dimensions obtained during the geometric assessment, discounting the decay depth detected by Pilodyn and Resistograph tests (see Figure 6).

\subsection{Loads}

For the analysis, two types of loads were applied on the truss. First, uniformly distributed loads, which were automatically 
computed, were imposed on the elements to represent the selfweight of the truss members. Subsequently, cyclic vertical loads were applied at the joints, simulating the loading history adopted in the load-carrying test.

\subsection{Semi-rigid modelling of connections}

Traditional timber joints, even without any kind of strengthening, usually have a significant moment capacity (Branco et al., 2011; Candelpergher and Piazza, 2001; Parisi and Piazza, 2000). Common constraint models, such as hinges or full restraint connections, cannot satisfactorily describe the real behaviour of these joints. However, in the case of the load-carrying test performed with symmetric loading, the rotational stiffness of connections has a trivial influence on the overall behaviour of the tested truss (Branco et al., 2008, 2010). However, the axial stiffness of the connections is crucial in the truss response (deformation and stress distribution).

The axial stiffness $\left(k_{\mathrm{ax}}\right)$ depends on the mechanical properties of the lumber, the geometric proportions of the connected elements and the connection angle (skew angle) (Piazza et al., 2004)

1. $k_{\mathrm{ax}}=\frac{E_{\alpha} S}{l}$

where, applying the Hankinson Equation 2

2. $E_{\alpha}=\frac{E_{0}}{\cos ^{2} \alpha+\left(E_{0} / E_{90}\right) \sin ^{2} \alpha}$

represents the wood elastic modulus in the direction forming an angle $\alpha$ with the fibre

3. $l=\frac{h}{2 \sin \alpha}$

represents the nominal notch length, where compression deformation occurred, and

4. $S=\frac{A_{\text {rafter }}}{\sin \alpha}$

represents the nominal notch area, where stress was assumed to be transmitted.

The axial stiffness of the tie beam-post connections $\left(k_{\mathrm{ax}, \mathrm{hs}}\right)$ has been formulated taking into account the axial stiffness of the heel strap

5. $k_{\text {ax }, \text { hs }}=\frac{E_{\text {steel }} A_{\text {heel strap }}}{l_{\text {heel strap }}}$ where $E_{\text {steel }}$ is the modulus of elasticity of steel, $A_{\text {heel strap }}$ and $l_{\text {heel strap }}$ are the cross-section and the length of the heel strap, respectively.

A detailed explanation of the above expressions and the parameters involved can be found in previous works such as Piazza et al. (2004) and Candelpergher and Piazza (2001), which are related to the numerical modelling of testing results of full-scale carpentry joints.

\section{Numerical compared with experimental results}

The first simulations were aimed at evaluating the reliability of the numerical model. The numerical analysis started with an investigation of the influence of stiffness of the joints. Results of a model with joints simulated as hinges were compared with a similar model but with rigid joints. In both models, the cross-sections measured in the visual inspection, without taking into account the degradation depth (effective crosssection of the truss members), were assumed. Despite the differences between displacement levels, rigid joints led to smaller values of vertical displacements. Neither model was able to represent the asymmetric response of the truss observed (see Figure 18).

The asymmetric response was reproduced only for the models where the cross-section of the beam elements had taken into account the wood deterioration. This outcome emphasises, once again, the importance of the diagnosis phase - in particular, the adequate assessment of the effective cross-sections of the timber members - for a reliable study of the behaviour of timber trusses in old constructions.

After the validation of the options taken in terms of the model for the joints (axial stiffness) and for the timber elements (beam elements with an effective cross-section measured for each $40 \mathrm{~cm}$ length), the results of the numerical model were compared with those recorded during the load-carrying test. Comparing the results of the maximum vertical displacement of the truss measured during the load-carrying test and those obtained from the numerical model assuming the theoretical values for the joints' axial stiffness, the latter values are only $28 \%$ of the former (see Table 2). From this, it was clear that the theoretical values for the axial stiffness of the joints were too large. The overall wood decay, especially at areas of higher stress concentration (joints), and the visible joint gaps, significantly reduced the initial axial stiffness of the joint. Despite the joint gaps identified in the visual inspection being filled with wood (Figure 3), the joint axial stiffness was not restored. So, a calibration process of the model was undertaken by reducing the axial stiffness values assumed for the joints. Numerically, adopting this simple model but reducing the axial stiffness of the joints, it is possible to simulate the response of the joints during the load-carrying tests described 


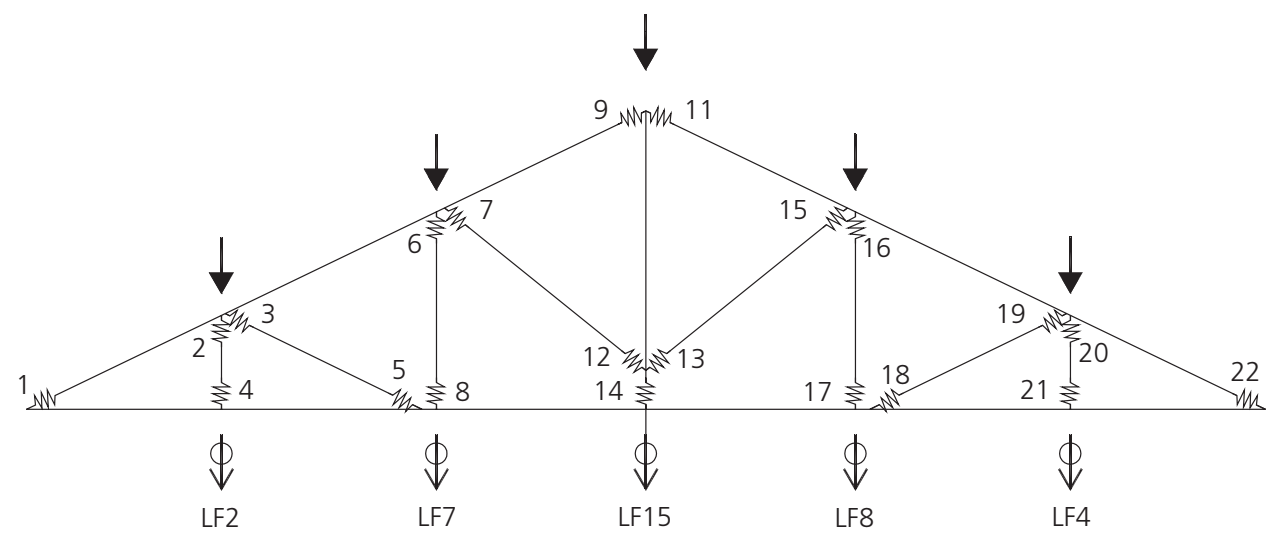

\begin{tabular}{|c|c|c|c|c|c|c|c|c|c|c|}
\hline \multirow[b]{3}{*}{ Tests results } & \multicolumn{2}{|c|}{ LF2 } & \multicolumn{2}{|c|}{ LF7 } & \multicolumn{2}{|c|}{ LF15 } & \multicolumn{2}{|c|}{ LF8 } & \multicolumn{2}{|c|}{ LF4 } \\
\hline & $\delta: \mathrm{cm}$ & $\Delta: \%$ & $\delta: \mathrm{cm}$ & $\Delta: \%$ & $\delta: \mathrm{cm}$ & $\Delta: \%$ & $\delta: \mathrm{cm}$ & $\Delta: \%$ & $\delta: \mathrm{cm}$ & $\Delta: \%$ \\
\hline & $4 \cdot 36$ & & $6 \cdot 49$ & & $6 \cdot 61$ & & $6 \cdot 69$ & & $5 \cdot 42$ & \\
\hline \multicolumn{5}{|l|}{ Joints axial stiffness } & \multicolumn{6}{|c|}{ Numerical model } \\
\hline Theoretical & $1 \cdot 23$ & 72 & $1 \cdot 80$ & 72 & $1 \cdot 81$ & 73 & $1 \cdot 88$ & 74 & 1.42 & 72 \\
\hline$\Delta_{30 \%}$ & $2 \cdot 62$ & 40 & $3 \cdot 60$ & 45 & $3 \cdot 46$ & 48 & $3 \cdot 76$ & 48 & $2 \cdot 80$ & 45 \\
\hline$\Delta_{20 \%}$ & $3 \cdot 41$ & 22 & 4.98 & 23 & 4.92 & 26 & $4 \cdot 61$ & 39 & $3 \cdot 32$ & 28 \\
\hline$\Delta_{10 \%}$ on Nlink no. 22 & 3.97 & 9 & $5 \cdot 94$ & 8 & 6.04 & 9 & $5 \cdot 45$ & 34 & $3 \cdot 59$ & 16 \\
\hline$\Delta_{5 \%}$ on Nlink no. 22 & $4 \cdot 22$ & 3 & $6 \cdot 56$ & 1 & $7 \cdot 06$ & 7 & $6 \cdot 81$ & 8 & 4.97 & 4 \\
\hline \multicolumn{11}{|c|}{$\Delta_{i} \%$ reduction of joint axial stiffness $\left(k_{\mathrm{ax}}\right)$ in comparison with theoretical values $\left(10^{3} \mathrm{kN} / \mathrm{m}^{2}\right)$} \\
\hline Nlink no. $\quad 1$ & 2 & 3 & 4 & 5 & 6 & 7 & 8 & 9 & 11 & 12 \\
\hline 379 & 24 & 108 & 23 & 228 & 23 & 97 & 22 & 87 & 84 & 117 \\
\hline Nlink no. & 14 & 15 & 16 & 17 & 18 & 19 & 20 & 21 & 22 & \\
\hline 109 & 20 & 92 & 25 & 23 & 264 & 113 & 24 & 23 & 412 & \\
\hline
\end{tabular}

Table 2. Comparison of the maximum vertical displacement $(\delta$ ) of the truss measured during loading and those obtained with the numerical model

in Section $4 \cdot 5$, and its consequence on the overall deformation of the truss.

Reducing the theoretical values of the axial stiffness of the joints by $20 \%$, an average error of $28 \%$ was obtained when comparing the numerical results with the experimental ones. However, the observed non-symmetric deformation of the tie beam was not reproduced by the numerical model. Based on the observations during the load-carrying test, especially taking into account the failure mode, it was decided to increase the reduction of the axial stiffness of the right rafter-tie beam joint (Nlink no. 22). When this local reduction reached $5 \%$ of the initial values, a good match was obtained between the numerical model results and the response obtained in the load-carrying test. Table 2 presents the comparison of the maximum vertical displacements of the truss measured during the load-carrying test and the corresponding values obtained with the numerical model for the most representative simulations.

In this calibration process, the material properties assumed for the wood were not taken into account because no wood mechanical characterisation was performed. Non-destructive tests were conducted to assess the effective cross-section of the truss components. In this case, however, their ability to predict the wood material properties is limited in the absence of destructive tests, and because no reliable correlations between the test results and the material properties are known for this particular wood species. Moreover, the test performed demonstrated that the overall response of the timber truss is governed 
by the behaviour of the joints, in particular, by their axial stiffness, and by the existence of defects detected by visual inspection.

\section{Conclusions}

The full-scale test conducted proved to be an important method to assess the overall performance of traditional timber trusses, and was able to point out the localised behaviour of joints. The experimental programme yielded information and data that would be difficult to assess using a different approach. The reasons why such tests are not particularly common are related to the scale of the experimental campaign, in terms of the equipment and human resources that are required.

The test conducted demonstrated that, after minor interventions aiming to recover the original joint mechanisms' behaviour, the overall original behaviour of timber trusses can be restored. The response is linear elastic with the non-linear behaviour concentrated at the joints. In fact, the joints are the key elements in the overall behaviour of the truss. The truss that was tested presented localised damage at the joint between the rafters and the tie beam, which conditioned the failure mode of the system. Those joints are critical for the overall behaviour of this kind of timber truss and, at same time, they are the ones more susceptible to degradation. Therefore, assessment of the wood material, pointing out local defects or damage, is crucial for an accurate interpretation and analysis of the global behaviour of existing timber trusses. The truss failed due to local damage detected previously, during visual inspection of the truss.

A simple numerical model was implemented to reproduce the test carried out. This again proved that the diagnosis phase was crucial to define the effective cross-sections of the truss members. The non-symmetrical response observed during the load-carrying test was simulated only when the correct effective cross-sections of the truss elements, taking into account the degradation depth measured by the NDTs performed, was considered in the beam elements of the model. Then, as the loading procedure is symmetric, it is the joint axial stiffness that plays a crucial role in the response of the numerical model. The following simulations demonstrated that reducing the joint axial stiffness, in order to take into account the existence of gaps and local degradation of joints, significantly increases the accuracy of the numerical model. The trial-anderror process followed during modelling emphasises the need for defining a scientific procedure for the reduction of joint axial stiffness.

Another source of discrepancy in the numerical results can be attributed to the material properties assumed for the wood. However, in practice, designers adopt the material properties values contained in the literature without considering the possibility of carrying out a structural assessment based on reliability methods, as desired. Therefore, the authors chose to retain the material properties assumed in the numerical models.

As a final conclusion, it is suggested that a methodology should be developed to define how the gaps and initial damage and/or decay observed at the joints during the preliminary visual inspection can be taken into account in the joint axial stiffness reduction. There is detailed information available on the definition of the effective cross-section of timber elements, their material properties and the expression of the joint axial stiffness, but no information exists on how this stiffness is influenced by gaps and degradation. Full-scale tests, as the one presented here, represent the best methodology to assess how the damage observed on the joints reflects itself in the overall behaviour of existing timber trusses. Therefore, such tests should be performed at every opportunity.

\section{Acknowledgements}

The authors would like to acknowledge the cooperation of Adico in allowing the rescue of the timber truss during restoration works at their facilities.

\section{REFERENCES}

Arêde A, Noites L and Costa A (2004) Sistemas de Monitorização de Ensaios de Estruturas de Engenharia Civil em Laboratório. NI Days, LNEC, Lisbon, Portugal (in Portuguese).

Bertolini-Cestari C, Invernizzi S, Marzi T and Rolla S (2013) Preservation of the large timber roof of the Porta Nuova railway station in Torino. Advanced Materials Research 778(9): 951-958.

Branco JM, Cruz PJS, Piazza M and Varum H (2008) Field tests of a timber queen-post truss and numerical analysis. Proceedings of SAHC 2008 - Structural Analysis of Historical Constructions, Bath, UK, pp. 507-513.

Branco JM, Piazza M and Cruz PJS (2010) Structural analysis of two king-post timber trusses. Nondestructive evaluation and load-carrying tests. Construction and Building Materials 24(3): 371-383.

Branco JM, Piazza M and Cruz PJS (2011) Experimental evaluation of different strengthening techniques of traditional timber connections. Engineering Structures 33(8): 2259-2270.

Calderoni C, De Matteis G, Giubileo C and Mazzolani FM (2010) Experimental correlations between destructive and non-destructive tests on ancient timber elements. Engineering Structures 32(2): 442-448.

Candelpergher L and Piazza M (2001) Mechanics of traditional connections with metal devices in timber roof structures. Proceedings of the 7th International Conference STREMAH, Bologna, Italy, pp. 415-424. 
CEN (European Committee for Standardization) (1994) EN 350-2: Durability of wood and wood-based products - Natural durability of solid wood - part 2: guide to natural durability and treatability of selected wood species of importance in Europe. European Committee for Standardization (CEN), Brussels, Belgium.

Cruz H, Yeomans D, Tsakanika E et al. (2015) Guidelines for the on-site assessment of historic timber structures. International Journal of Architectural Heritage 9(3): 277-289.

Del Senno M and Piazza M (2003) Behaviour and rehabilitation of queen post timber trusses. A case study. Proceedings of STREMAH 2003: Structural Studies, Repairs and Maintenance of Heritage Architecture VIII,Halkidiki, Greece.

Descamps T, Léoskool L, Laplume D, Van Parys L and Aira JR (2014) Sensitivity of timber hyperstatic frames to the stiffness of step and ridge joints. Proceedings of World Conference on Timber Engineering, Quebec, Canada.

Dietsch P and Kreuzinger H (2011) Guideline on the assessment of timber structures: summary. Engineering Structures 33(11): 2983-2986

Drdácký M, Wald F and Sokol Z (1999) Sensitivity of historic timber structures to their joint response. Proceedings of 40th Anniversary Congress of the IASS, Madrid, Spain.

Ficha M2 (1997) Timber for Structures - Maritime Pine for Structures. LNEC National Laboratory of Civil Engineering. LNEC, Instituto Português da Qualidade, Portugal (in Portuguese).

Frühwald E (2011) Analysis of structural failures in timber structures: typical causes for failure and failure modes. Engineering Structures 33(11): 2978-2982.

Kasal B (2011) In Situ Assessment of Structural Timber - State of the Art Report of the RILEM Technical Committee 215-AST (Kasal B and Tannert T (eds)). Springer, the Netherlands.
Mackerle J (2005) Finite element analyses in wood research: a bibliography. Wood Science and Technology 39(7): 579-600.

Parisi MA and Piazza M (2000) Mechanics of plain and retrofitted traditional timber connections. Journal of Structural Engineering, ASCE 126(12): 1395-1403.

Piazza M, Brentari G and Riggio MP (2004) Strengthening and control methods for old timber trusses: the queen-post truss of the Trento theatre. Proceedings of SAHC 2004: Structural Analysis of Historical Constructions, Padova, Italy, vol. II, pp. 957-965.

Riggio M, Anthony RW, Augelli F et al. (2013) In situ assessment of structural timber using non-destructive techniques. Materials and Structures 47(5): 749-766.

Rinn F (1992) Chancen und grenzen bei der untersuchung von konstruk-tionsholzern mit der bohrwiderstandsmethode. Bauen mit Holz 9: 745-748.

Santos VDR (2009) Evaluation of the Behavior of Large Old Timber Trusses. Master thesis, Department of Civil Engineering, University of Aveiro, Aveiro, Portugal (in Portuguese).

SAP (Structural Analysis Program) (2000) Static and Dynamic Finite Element Analysis of Structures. Structural Analysis Program, Computers and Structures, Inc., Advanced 9.03, Berkeley, CA, USA.

UNI (Ente Nazionale Italiano di Unificazione) (2003) UNI 11035-1: Structural timber - visual strength grading for Italian structural timbers: terminology and measurement of features. Ente Nazionale Italiano di Unificazione, Milano, Italy.

Uzielli L (2004) Il Manuale del Legno Strutturale, Vol IVInterventi Sulle Strutture. Mancosu, Rome, Italy (in Italian). 